\title{
A stereological study of 3D printed tissues engineered from rat vaginas
}

\author{
Yanpeng Tian, Shuangdan Zhao, Jiahua Zheng, Zhongkang Li, Chenxiao Hou, Xuejun Qi, \\ Desheng Kong, Jingkun Zhang, Xianghua Huang
}

Department of Obstetrics and Gynecology, the Second Hospital of Hebei Medical University, Shijiazhuang, China

Contributions: (I) Conception and design: X Huang, J Zhang; (II) Administrative support: None; (III) Provision of study materials or patients: Y Tian, S Zhao, J Zhang; (IV) Collection and assembly of data: Y Tian, Z Li, C Hou; (V) Data analysis and interpretation: D Kong, X Qi; (VI) Manuscript writing: All authors; (VII) Final approval of manuscript: All authors.

Correspondence to: Xianghua Huang. Department of Obstetrics and Gynecology, the Second Hospital of Hebei Medical University, No. 215 West Heping Road, Shijiazhuang 050000, China. Email: huangxh2003@163.com.

Background: This study aims to retrieve the stereological data from rat vaginas for 3D printing tissueengineered vaginas.

Methods: In this study, five female Sprague-Dawley rats, aged 8-12 weeks, were used to obtaining the vagina tissues. Each vagina was divided into eight segments fixed in $4 \%$ paraformaldehyde and embedded in paraffin, whose two consecutive sections of each block were stained using hematoxylin and eosin (H\&E) and anti- $\alpha$-actin antibody with immunohistochemistry staining, respectively. The thickness of the epithelium, lamina propria, the smooth muscle layer, and the adventitia layer are measured. Then, the volume density of the epithelial cells and smooth muscle cells are counted using design-based stereology.

Results: The length and width of the rat vaginas were 2 and $1.5 \mathrm{~cm}$, respectively. The thickness of the epithelium, lamina, propria, and adventitia layer was measured, and no significant difference was observed. However, the thickness of the smooth muscle layer was significantly different among these eight segments. The smooth muscle layer of the lower vagina is thicker than the upper vagina. The average volume density of epithelial cells and smooth muscle cells is $1.61 \times 10^{9} / \mathrm{cm}^{3}$ and $5.38 \times 10^{8} / \mathrm{cm}^{3}$. There was a significant difference observed.

Conclusions: We had successfully retrieved the stereological data of the vaginas. The gained data will supply us with the information for $3 \mathrm{D}$ printing vaginas and new insights into the structure of the vagina.

Keywords: Vagina reconstruction; 3D printing; tissue engineering; stereology

Submitted Aug 13, 2020. Accepted for publication Nov 06, 2020.

doi: 10.21037/atm-20-6347

View this article at: http://dx.doi.org/10.21037/atm-20-6347

\section{Introduction}

The vagina is a muscular tube, which plays a crucial role in sexual intercourse and the uterine outlet for menstruation and childbirth. Vagina reconstruction is needed for many patients because of congenital vaginal aplasia or acquired diseases, including a gynecological tumor, trauma, and maleto-female sex surgery. There are several approaches, both surgical and nonsurgical, to reconstruct the vagina. Owing to the feelings of embarrassment and shame caused by long-term of dilator use, patients prefer surgical methods, dissecting the potential neo-vaginal space with subsequent lining with a graft. However, many complications are associated with these methods, including contracture, necrosis, prolapse, intestinal obstruction, and malignancy. Therefore, to explore an ideal vaginoplasty is necessary.

In recent years, biomaterials and tissue engineering techniques are used to reconstruct the vagina, including decellularized matrices (1), small intestinal submucosa (SIS) (2), and buccal mucosa (3), among many others. Zhu et al. used an acellular dermal matrix $(\mathrm{ADM})$ to reconstruct the vagina 
for 53 patients and retrieved satisfactory outcomes (1). Raya-Rivera et al. recreated vaginas for four patients via transplanting the SIS seeding epithelial and smooth muscle cells (4). The acellular matrix derived from a heterogeneous organism may cause a severe immunologic response. Also, materials derived from autologous tissue may cause donor site morbidity.

The emergence of $3 \mathrm{D}$ printing technology $(5,6)$ provides a new possible method for vagina reconstruction. This technology is widely applied in bone reconstruction and plastic surgery. In gynecology, 3D printing is widely applied in pelvic reconstruction, based on the CT datasets of the pelvic structure and digital three-dimensional reconstruction. However, it has not been applied in tissue engineering and regeneration. The bioprinting systems are from cells, biomaterials, and stereological data, which can regenerate a functional tissue and organ. In a previous study, we have induced rat bone marrow mesenchymal cells into epithelial cells, smooth muscle cells, and endothelial cells (7). A new biomaterial for vaginal reconstruction was used to reconstruct the vagina, the acellular vagina matrix (AVM) (8). Compared with other biomaterials, AVM can promote the formation of neo-vagina more rapidly. And we are preparing AVM into hydrogels that can be used for bioprinting. Therefore, we supposed that a cell compound with a hydrogel produced by the acellular vagina matrix might be the ideal procedure for reconstruction vagina. The origin of the upper and lower vagina is different. The stereological data is the basis for vaginal reconstruction by $3 \mathrm{D}$ printing. In this study, we aim to use design-based stereology to retrieve the stereological data of normal rats' vaginas to obtain the accurate cell density from different segments, which will provide us the data to reconstruct the $3 \mathrm{D}$ bioprinting vagina.

We present the following article in accordance with the ARRIVE reporting checklist (available at http://dx.doi. org/10.21037/atm-20-6347).

\section{Methods}

\section{Animals}

The Animal Ethics Committee has approved all the experimental protocols of the Second Hospital of Hebei Medical University (Certificate number: 2020 R109). Experiments were performed in compliance with NIH guidelines for the care and use of animals. Five female Sprague-Dawley rats (Hebei Medical University, Shijiazhuang, China. Certificate number: 1912121) aged
8-12 weeks and with average weight from 200 to $250 \mathrm{~g}$ were used in this study.

\section{Tissue processing}

Rats were anesthetized with $0.1 \%$ pentobarbital sodium $(40 \mathrm{mg} / \mathrm{kg})$ intraperitoneal injection. The entire vaginal tissue was acquired via a midline transabdominal approach. Then, the vaginal tissues were divided into eight segments on average, which were fixed in $4 \%$ paraformaldehyde and embedded in paraffin. Each block is sectioned from the proximal vulva $(15 \mu \mathrm{m})$.

\section{Hematoxylin-eosin staining}

Paraffin sections with a thickness of $4 \mu \mathrm{m}$ were obtained and routinely dewaxed and washed with xylene. The slices were stained with eosin solution for $3 \mathrm{~min}$ and then washed with phosphate buffer saline (PBS). The slices were then dehydrated in alcohol (from a low to high concentration) and sealed with neutral resin. The thickness of the epithelial layer and volume density of epithelial cells are measured and counted in the H\&E staining sections under a normal microscope (Nikon Corporation).

\section{Immunobistochemistry staining}

Paraffin sections with a thickness of $4 \mu \mathrm{m}$ were routinely dewaxed. The slices were incubated with $3 \% \mathrm{H}_{2} \mathrm{O}_{2}$ at room temperature for 5-10 minutes to eliminate endogenous peroxidase activity. The slices were washed with PBS for 3 times, 5 min each time and then blocked with $5 \%$ serum. Anti- $\alpha$-actin antibody (1:100; Santa Cruz) was added to the section at $4{ }^{\circ} \mathrm{C}$ overnight. The next day, the sections were incubated with Secondary Antibody (1:500; Santa Cruz) at room temperature for 2 hours and stained with DAB. Finally, the smooth muscle layer, and adventitia, the thickness of the three layers and volume density of smooth muscle cells are measured and counted under a normal microscope (Nikon Corporation).

\section{Stereology analysis}

The sections stained by $\mathrm{H} \& \mathrm{E}$ and immunohistochemistry staining were viewed using an Olympus BH-2 microscope, whose cell density and thickness of all four layers of vaginal wall were measured using design-based stereology by software (Cell Sens Dimension 1.18). The stereological 

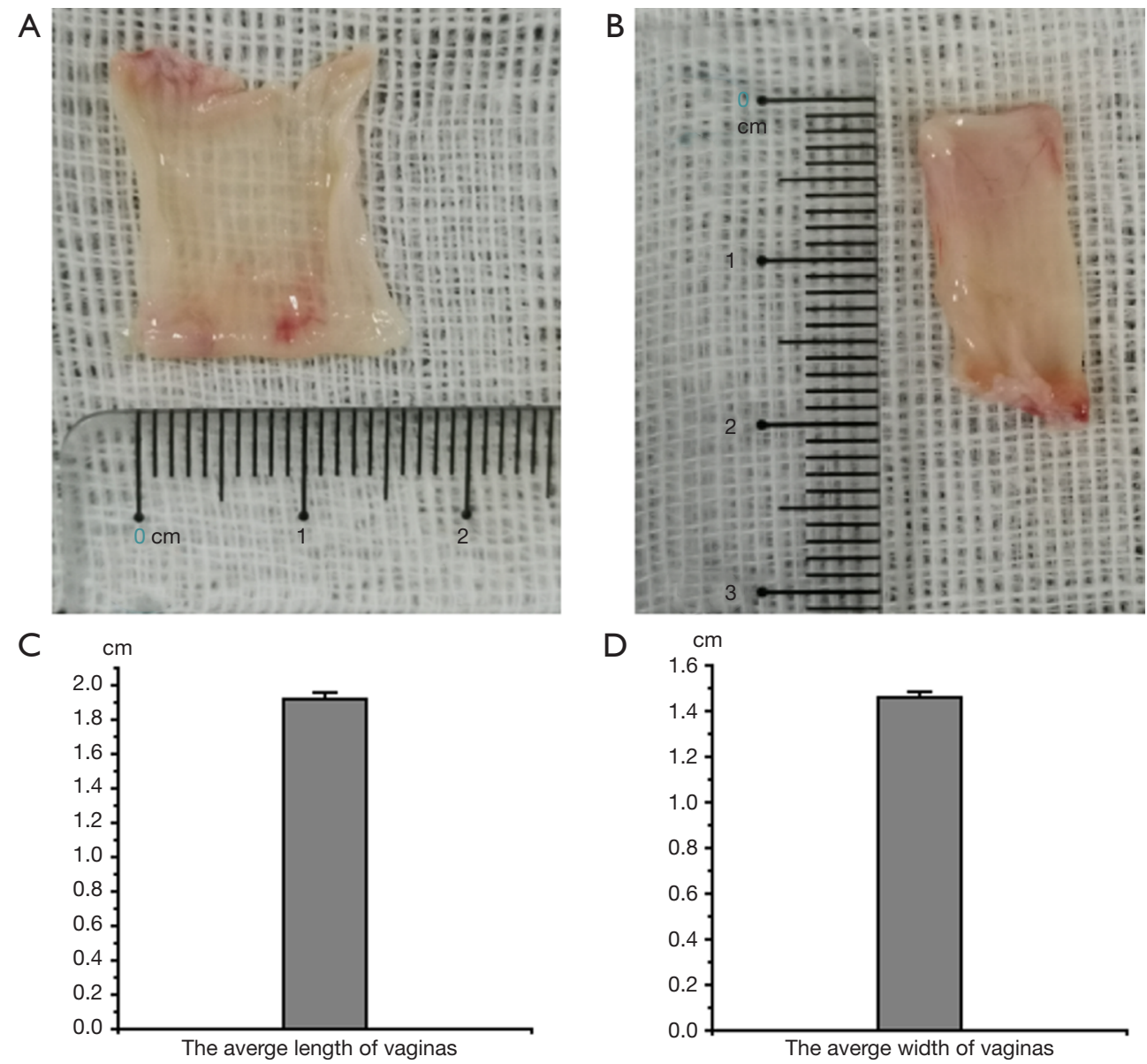

Figure 1 The length and width of vaginas. (A,B) Measurements of gross morphology; (C) the average length of the vagina; (D) the average width of vaginas.

unbiased counting frames $(22 \mu \mathrm{m} \times 15 \mu \mathrm{m})$ were superimposed on to the images viewed on the monitor to count cell density (9). An oil objective lens is used while counting the number of cells. The total cell density is calculated via the formula:

$N V$ (the number of cells / volume of vields) $\sum Q /\left[\sum P \times \alpha(f) \times h\right]$

Where $\sum Q$ was the number of cells computed inside the counting frame, provided not touch or intersect the left, the bottom and the extension lines, $\Sigma P$ was several disectors, $a(f)=330 \mu \mathrm{m}^{2}$ was the region of the unbiased counting frame, and $b=5 \mu \mathrm{m}$ was the altitude of the disector. Also, the upper and lower $3 \mu \mathrm{m}$ of each section were considered guard zones by a microcator.

\section{Statistical analysis}

Statistical analysis was performed using SPSS 21.0. Data were analyzed by one-way analysis of variance (ANOVA) and presented by mean \pm SEM differences were considered significant at $\mathrm{P}<0.05$.

\section{Results}

To reconstruct the $3 \mathrm{D}$ bioprinting vagina, we should know the scale of the vagina. The length and width of the five vaginas were measured. Data are shown in Figure 1. These results showed the scale of vaginas and showed us information for $3 \mathrm{D}$ printing.

The vaginal wall comprises four layers; epithelium, lamina propria, smooth muscle layer, and adventitia. We measure the thickness of the epithelium via the HE stains. Immunohistochemical staining for $\alpha$-actin was used to measure the smooth muscle layer and the lamina propria and adventitia, which can separate the lamina propria, smooth muscle layer, and adventitia. Data are shown in 
A

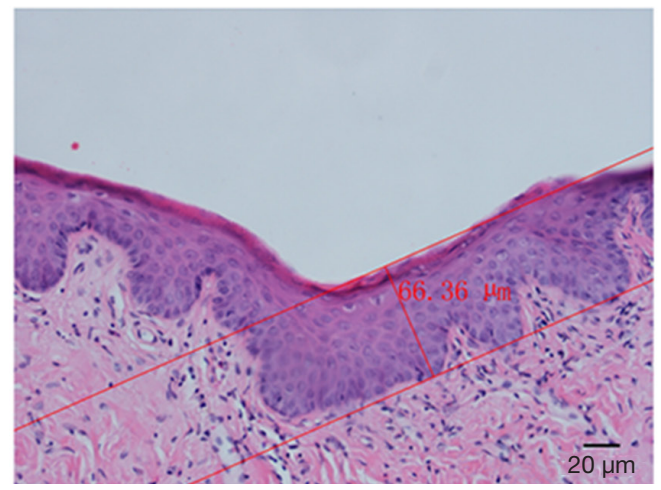

B

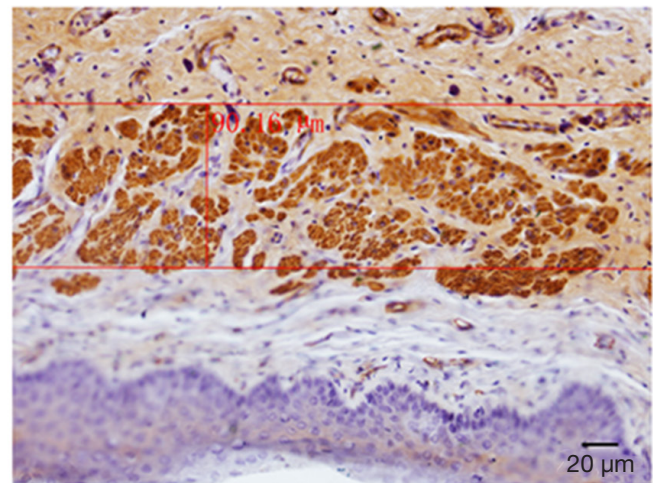

E
C
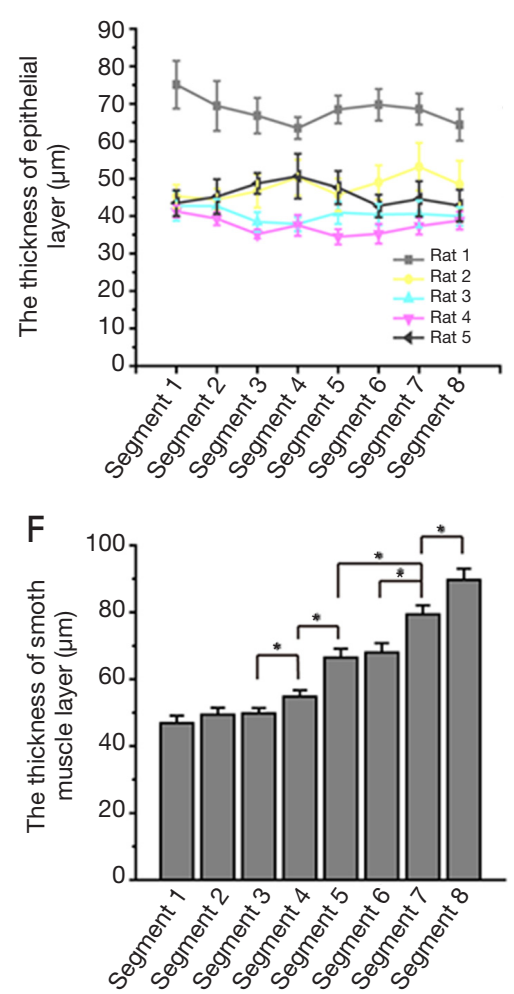

D

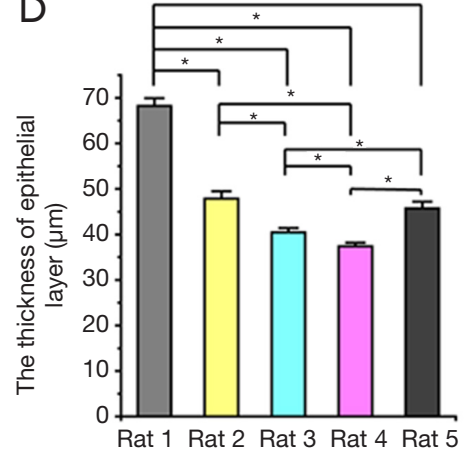

G

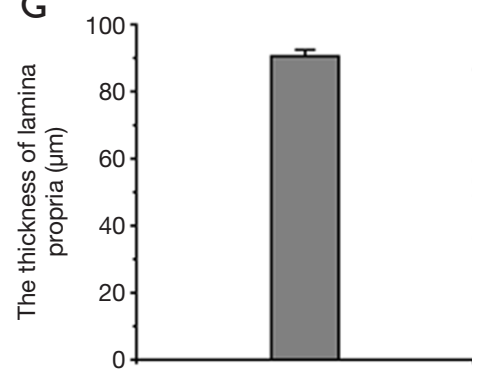

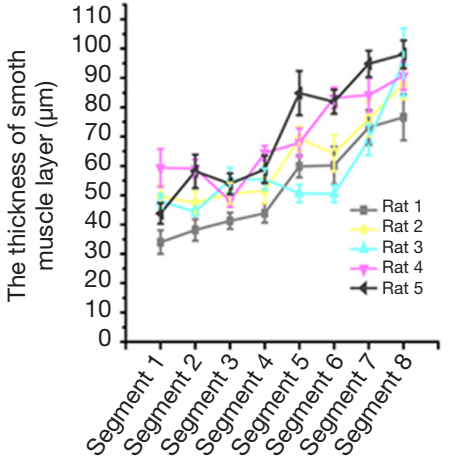

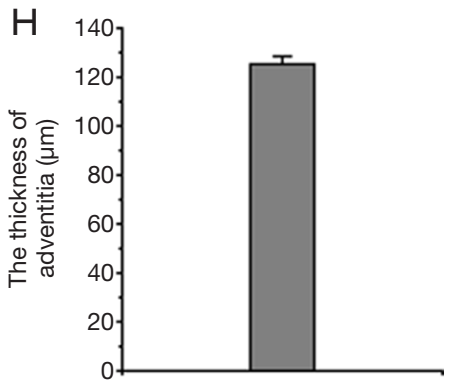

Figure 2 Thickness of epithelium, lamina propria, the smooth muscle layer, and adventitia. (A,C,D) The thickness of the epithelium. Significant differences were observed among rats, but not among segments (stained with hematoxylin and eosin). (B,E,F) The thickness of smooth muscle layers (anti- $\alpha$-actin antibody immunohistochemical staining). Significant differences observed among segments indicated thickness of upper and lower vaginal smooth muscle layers were different. (G) The thickness of lamina propria. (H) The thickness of the adventitia. *, $\mathrm{P}<0.05$.

Figure 2. All these results supply us with information about the thickness of four layers for $3 \mathrm{D}$ bioprinting vaginal tissues. There was no significant difference among different segments in the epithelium's thickness, lamina propria (data were not shown), and adventitia layers (data were not shown). The thickness of smooth muscle layers was significantly different among these segments. The lower segment of the vagina is thicker than the upper segment.

Epithelial cells and smooth muscle cells are the two fundamental types of cells in vaginal tissue. The volume density of epithelial cells and smooth muscle cells is counted using the 2-dimensional unbiased counting frame- 

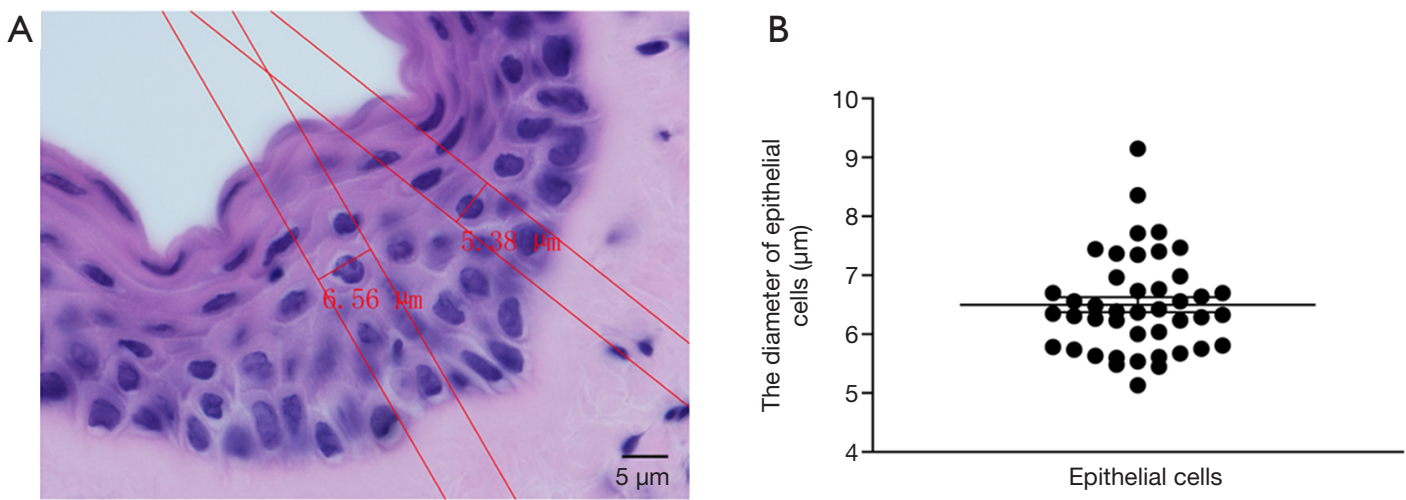

Figure 3 The diameter of epithelial cells. (A) The image of measurements of epithelial cells (stained with hematoxylin and eosin); (B) results of the diameter of epithelial cells (anti- $\alpha$-actin antibody immunohistochemical staining).

the optical dissector to reconstruct a vagina like a normal vagina. Before counting, we must know the diameter of the cells. We could not figure out the boundaries of smooth muscle cells clearly, so we measured the diameter of epithelial cells to show the height of the counting frame. The results were shown in Figure 3. Following these results, the dissector is set to $5 \mu \mathrm{m}$ because the counting frame height should be less than the diameter of the cells.

In counting epithelial cells and smooth muscle cells, all the cells inside the counting frame provided no touch or intersection to the left, the bottom, and the extension lines were considered for counting. Epithelial cells are counted by H\&E staining, and the results are shown in Figure 4 and Table 1. Immunohistochemical staining counts smooth muscle cells for $\alpha$-actin, and the results are shown in Figure 5 and Table 1. These results showed there were no significant differences among segments in epithelial cells and smooth muscle cells, which showed us the volume density of the cells.

\section{Discussion}

Vaginal reconstruction aims to create an integrated structure and a functional vagina. Nonsurgical and surgical procedures are both available. According to the American College of Obstetrician and Gynecologists, the progressive dilatation technique, raised by Frank, should be the first choice (10). Although satisfactory outcomes can be achieved (11), the feelings of embarrassment and shame of using dilators for the long term can cause patients to prefer surgical procedures (12). The most popular procedure is to dissect a patent tunnel between bladder and rectum, then subsequently covered by biomaterials (13). Several biomaterials, to date, were applied to reconstruct the vagina, including skin flaps (14), myocutaneous flaps (15), amniotic membrane (16), peritoneum (17), buccal mucosa (3), intestinal segments (18), and decellularized matrices (1). However, these studies proved that so many complications are associated with these biomaterials, including donor site morbidity, extensive surgery, contracture and stenosis, excess mucous production, and possible malignancy. Overall, searching for an ideal procedure is necessary.

Several alternative methods were applied to reconstruct the vagina via tissue engineering technology. The epithelial cells and smooth muscle cells, retrieved from vaginas, were seeded onto the opposite side of the polyglycolic acid (PGA) scaffold to reconstruct vaginas (19). After six months, a neovagina was successfully created. Also, autologous epithelial and muscle cells were seeded into SIS by the same approach. Then these constructs were transplanted to four patients with congenital vaginal aplasia. Functional outcomes were retrieved after eight years (4). With the development of 3D printing technology, it is possible to reconstruct tissues or organs using cells and hydrogel created by biodegradable materials $(5,6)$. Kang et al. (5) has successfully produced the human-scale tissue constructed with structural integrity via 3D printing technology. The acellular vagina matrix (AVM) was used to reconstruct vaginal replacements in our previous study, and functional outcomes were retrieved (8). And we are preparing AVM into hydrogels that can be used for bioprinting. Therefore, we supposed that a cell compound with a hydrogel produced by the acellular vagina matrix might be the ideal procedure for reconstruction vagina. We have induced rat bone marrow mesenchymal cells to differentiate into epithelial cells, smooth muscle cells, and endothelial cells in our previous study (7). Therefore, we 

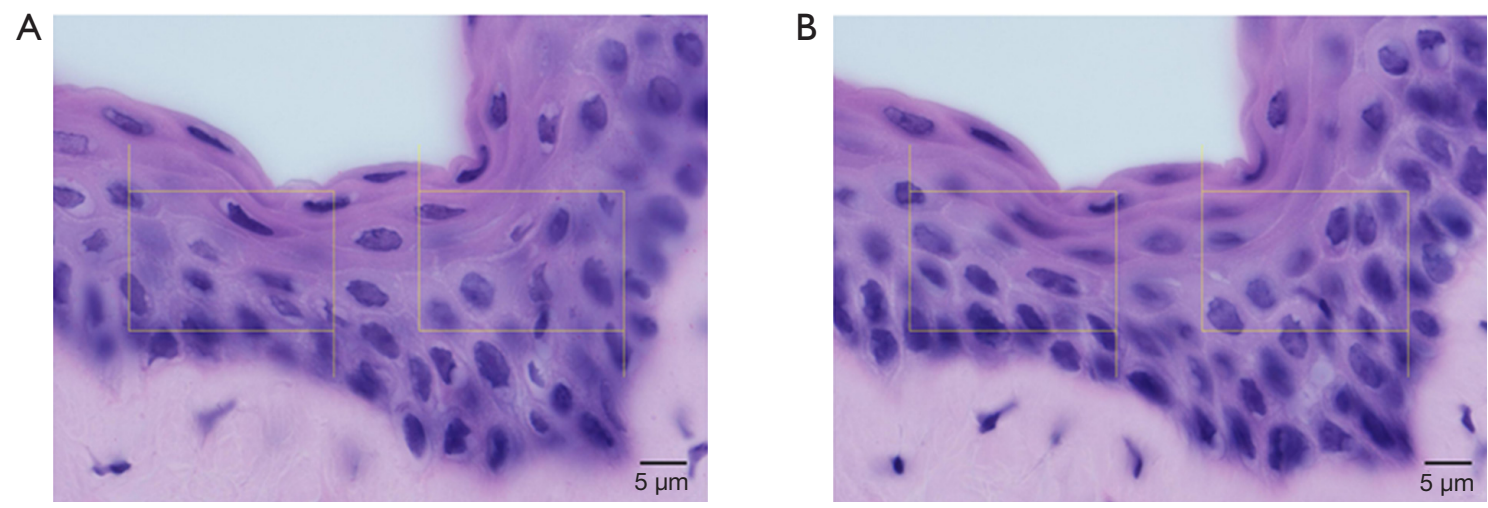

C

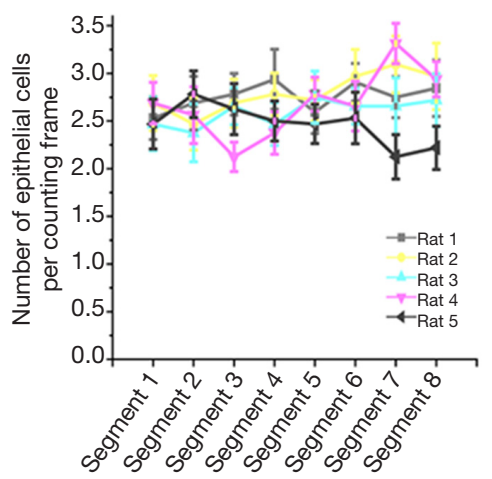

D

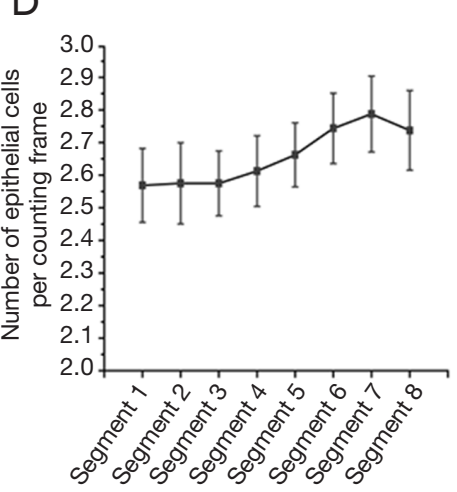

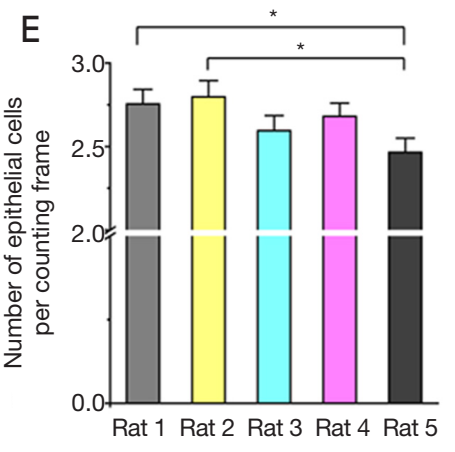

Figure 4 The volume density of epithelial cells. (A,B) Images of two stereological unbiased counting frames (stained with hematoxylin and eosin); (C) the number of epithelial cells per counting frame in different segments per rat; (D) the number of epithelial cells per counting frame in different segments from all rats; (E) average of epithelial cells from all counting frames per rat. A significant difference was observed among rats. *, $\mathrm{P}<0.05$.

Table 1 Volume density of epithelial cells and smooth muscle cells

\begin{tabular}{lccc}
\hline Parameters & No. of counting frames & No. of cells counted & ${\text { Volume density }\left(\mathrm{cm}^{3}\right)}^{3}$ \\
\hline Epithelial cells & 1,280 & 3,395 & $1.61 \times 10^{9}$ \\
Smooth muscle cells & 1,600 & 1,420 & $5.38 \times 10^{8}$ \\
\hline
\end{tabular}

aim to reconstruct vaginas using these differentiated cells with hydrogel. Before this, the stereology data of vaginas should be acquired. In this study, we aim to use designbased stereology to retrieve the stereological data of a normal vagina.

As known, the origin of the upper and lower segments of the vagina is different (20). That is why we divided the vagina into eight segments to measure and count the scale and cell number of different segments, respectively. First, we measured the length and width of normal vaginas, and then the thickness of the epithelium, lamina propria, smooth muscle layer, and adventitia was retrieved by the
HE staining and immunohistochemical staining. These results showed that the smooth muscle layer is significantly different among these segments. Vaginal reconstruction aims to create a functional vagina. However, we never took whether the four layers and volume density of cells of the upper and lower vaginal wall were the same into consideration. Our results showed a smooth muscle layer of the lower vagina is thicker than the upper vagina in the rat. Whether the same situation exists in human beings needs further exploration. In a word, these data will supply us with the vaginal scale to reconstruct the $3 \mathrm{D}$ bioprinting vagina and bring new insights into the vaginal structure. 


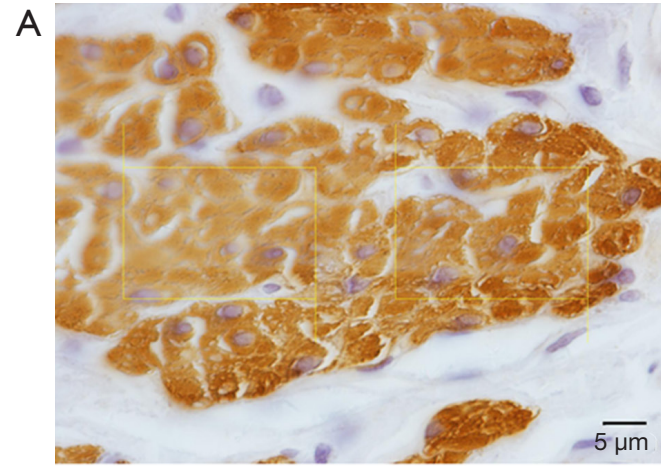

C

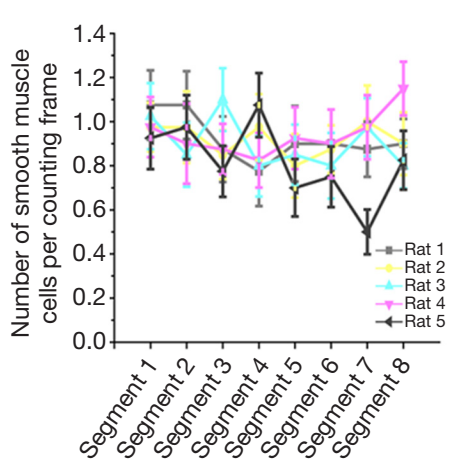

D

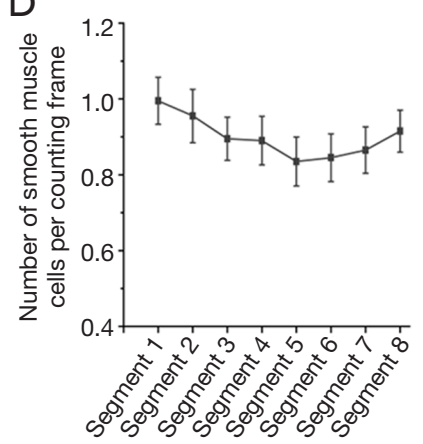

B

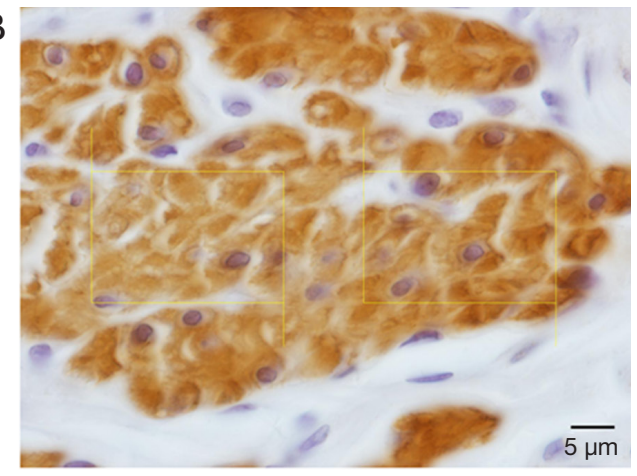

$\mathrm{E}$

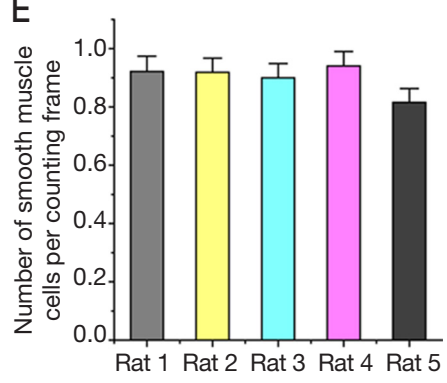

Figure 5 The volume density of smooth muscle cells. (A,B) Images of two stereological unbiased counting frames (anti- $\alpha$-actin antibody immunohistochemical staining); (C) the number of smooth muscle cells per counting frame in different segments per rat; (D) the number of smooth muscle cells per counting frame in different segments from all rats; (E) average of smooth muscle cells from all counting frames per rat.

The volume density of epithelial cells and smooth muscle cells is counted using the 2-dimensional unbiased counting frame. Results showed that epithelial cells and smooth muscle cells were uniformly distributed between the upper and lower segments of the vagina. All these data will supply us with a reasonable basis for the number of cells we compound in biomaterials and show us novel insights into vaginal structure.

However, there are some shortcomings in this study. Stromal cells and vessels are not counted. Therefore, we hypothesize two approaches to reconstruct blood vessels. Neovascular will spontaneously penetrate the neovagina after the constructs are transplanted into animals. Besides, we can use an extremely fine needle to penetrate the constructs to create tunnels so that differentiated endothelial cells can be cultured in the tunnels to form neovascular. After a neovascular grows into the neo-vagina, stromal cells will also grow into the neo-vagina and be redistributioned. Owing to the limitation of experimental conditions and the tubular structure of the vagina, the stereology methods we used in this study were not totally unbiased, taking into account the format and randomness. Five animals were used in this study to decrease the error and ensure the accuracy of stereological data. This study supplies us with reasonable data of the vagina, though the data might not be the most perfect. This study can also help us re-understand the vaginal structure. How to take full advantage of these data to construct an integrated structural and functional vagina will be our next step. Therefore, some errors in this experiment are acceptable.

Although increased methods were used to reconstruct vaginas and the outcomes were better than before, each method has its disadvantages. The findings of this study and previous studies $(5,6)$ show that $3 \mathrm{D}$ printing technology may be the ideal procedure to reconstruct human-scale tissue constructs. However, there are many difficulties to reconstruct vagina in clinical application by $3 \mathrm{D}$ printing technology. There isn't any study on 3D printing tissueengineered vagina. And there are still many technical problems should be solved. Histo-compatibility, blood compatibility and degradation of the AVM hydrogel should be tested. Whether cells could grow well and 
maintain viability in AVM hydrogel should also be verified. Meanwhile, a large number of animal experiments need to be done to ensure AVM hydrogel containing cells could create an integrated structure and a functional vagina. Women are essential members of our society and the world. They have made significant contributions to the reproduction of the human world, so we must explore more perfect treatments to protect women's health.

\section{Conclusions}

There are significant differences between the upper and lower vagina in the thickness of the smooth muscle layer. The thickness of the epithelium, lamina propria, and adventitia between the upper and lower vagina were not significant differences, and the volume density of epithelial cells and smooth muscle cells.

\section{Acknowledgments}

The authors thank all members of the Department of Gynecology at the Second Hospital of Hebei Medical University and the Department of Pharmacology at Hebei Medical University for their scientific advice and encouragement.

Funding: This work was supported by the National Natural Science Foundation of China (No. 8167060210).

\section{Footnote}

Reporting Checklist: The authors have completed the ARRIVE reporting checklist. Available at http://dx.doi. org/10.21037/atm-20-6347

Data Sharing Statement: Available at http://dx.doi. org/10.21037/atm-20-6347

Conflicts of Interest: All authors have completed the ICMJE uniform disclosure form (available at http://dx.doi. org/10.21037/atm-20-6347). The authors have no conflicts of interest to declare.

Ethical Statement: The authors are accountable for all aspects of the work in ensuring that questions related to the accuracy or integrity of any part of the work are appropriately investigated and resolved. The experiment protocols were approved by Animal Ethics Committee of the Second Hospital of Hebei Medical University
(Certificate number: 2020-R109). Experiments were performed in compliance with NIH guidelines for the care and use of animals

Open Access Statement: This is an Open Access article distributed in accordance with the Creative Commons Attribution-NonCommercial-NoDerivs 4.0 International License (CC BY-NC-ND 4.0), which permits the noncommercial replication and distribution of the article with the strict proviso that no changes or edits are made and the original work is properly cited (including links to both the formal publication through the relevant DOI and the license). See: https://creativecommons.org/licenses/by-nc-nd/4.0/.

\section{References}

1. Zhu L, Zhou H, Sun Z, et al. Anatomic and sexual outcomes after vaginoplasty using tissue-engineered biomaterial graft in patients with Mayer-RokitanskyKuster-Hauser syndrome: a new minimally invasive and effective surgery. J Sex Med 2013;10:1652-8.

2. Ding JX, Zhang XY, Chen LM, et al. Vaginoplasty using acellular porcine small intestinal submucosa graft in two patients with Meyer-von-Rokitansky-Kuster-Hauser syndrome: a prospective new technique for vaginal reconstruction. Gynecol Obstet Invest 2013;75:93-6.

3. Lin WC, Chang CY, Shen YY, et al. Use of autologous buccal mucosa for vaginoplasty: a study of eight cases. Hum Reprod 2003;18:604-7.

4. Raya-Rivera AM, Esquiliano D, Fierro-Pastrana R, et al. Tissue-engineered autologous vaginal organs in patients: a pilot cohort study. Lancet 2014;384:329-36.

5. Kang HW, Lee SJ, Ko IK, et al. A 3D bioprinting system to produce human-scale tissue constructs with structural integrity. Nat Biotechnol 2016;34:312-9.

6. Burris NS, Hoff BA, Ross BD. Vascular Deformation Mapping (VDM) of thoracic aortic aneurysm: an application for color 3D printing in aortic disease. Ann Transl Med 2018;6:S123.

7. Zhang H, Zhang J, Huang X, et al. The Methods and Mechanisms to Differentiate Endothelial-Like Cells and Smooth Muscle Cells from Mesenchymal Stem Cells for Vascularization in Vaginal Reconstruction. Mol Biotechnol 2018;60:396-411.

8. Zhang JK, Du RX, Zhang L, et al. A new material for tissue engineered vagina reconstruction: Acellular porcine vagina matrix. J Biomed Mater Res A 2017;105:1949-59.

9. Shirazi M, Rajabalian MB, Noorafshan A, et al. The 
comparison of the effect of phenylephrine and epinephrine on penile spongy tissue in rats after experimental hypospadias surgery: a quantitative stereological study. BMC Urol 2019;19:55.

10. ACOG Committee Opinion No. 355: Vaginal agenesis: diagnosis, management, and routine care. Obstet Gynecol 2006;108:1605-9.

11. Edmonds DK, Rose GL, Lipton MG, et al. MayerRokitansky-Kuster-Hauser syndrome: a review of 245 consecutive cases managed by a multidisciplinary approach with vaginal dilators. Fertil Steril 2012;97:686-90.

12. Holt R, Slade P. Living with an incomplete vagina and womb: an interpretative phenomenological analysis of the experience of vaginal agenesis. Psychol Health Med 2003;8:19-33.

13. Nodale C, Vescarelli E, D'Amici S, et al. Characterization of human vaginal mucosa cells for autologous in vitro cultured vaginal tissue transplantation in patients with MRKH syndrome. Biomed Res Int 2014;2014:201518.

14. McINDOE A. The treatment of congenital absence and obliterative conditions of the vagina. Br J Plast Surg

Cite this article as: Tian Y, Zhao S, Zheng J, Li Z, Hou C, Qi X, Kong D, Zhang J, Huang X. A stereological study of 3D printed tissues engineered from rat vaginas. Ann Transl Med 2020;8(22):1490. doi: 10.21037/atm-20-6347
1950;2:254-67.

15. Morton KE, Davies D, Dewhurst J. The use of the fasciocutaneous flap in vaginal reconstruction. Br J Obstet Gynaecol 1986;93:970-3.

16. Morton KE, Dewhurst CJ. Human amnion in the treatment of vaginal malformations. Br J Obstet Gynaecol 1986;93:50-4.

17. Zhou JH, Sun J, Yang CB, et al. Long-term outcomes of transvestibular vaginoplasty with pelvic peritoneum in 182 patients with Rokitansky's syndrome. Fertil Steril 2010;94:2281-5.

18. Hendren WH, Atala A. Use of bowel for vaginal reconstruction. J Urol 1994;152:752-5; discussion 756-7.

19. Dorin RP, Atala A, Defilippo RE. Bioengineering a vaginal replacement using a small biopsy of autologous tissue. Semin Reprod Med 2011;29:38-44.

20. Klattig J, Englert C. The Mullerian duct: recent insights into its development and regression. Sex Dev 2007;1:271-8.

(English Language Editor: J. Chapnick) 